\title{
Pyrolysis of Tobacco Rob: Effect of Particle Size on Kinetic Study
}

\author{
Yi Yang ${ }^{1,2, a,{ }^{*}, \text { Gang Cheng }}{ }^{1}$, Xun Chen ${ }^{1}$, and Dundun Wang ${ }^{1}$ \\ ${ }^{1}$ State Grid Hunan Electric Power Corporation Research Institute, Changsha, China \\ ${ }^{2}$ Hunan Xiangdian Test Research Institute Co. Itd, Changsha, China
}

a yangyi07231@163.com

Keywords: TGA; TR; Conversion rate.

\begin{abstract}
During pyrolysis of tobacco rob (TR), the operating parameters such as the temperature, the heating rate, and residence time and particle size affect the process and result of the pyrolysis. Some of these parameters have been closely considered but the particle size of TR is often ignored. In this study, the size of TR particle was considered as a major factor in determining the mass loss in thermogravimetric analysis (TGA). The TGA results showed that the conversion rate increased and the activation energy decreased with a decrease in particle size. Minimizing the size of raw materials is an alternative method to improve the gas quality of TR pyrolysis.
\end{abstract}

\section{Introduction}

Taking into account the problems of greenhouse effect together with the decrease of fossil resources, biomass was considered to be a future renewable resource with a high potential for energy production [1]. Thermochemical conversion of biomass to produce liquid and gaseous fuels was one of the most attractive technologies in terms of energy and environment. Among the thermochemical processes, pyrolysis was a promising tool for providing bio-oil that could be used as fuel or chemical feedstock [2]. The pyrolysis of biomass was a very old energy technology that was again becoming attractive among various systems for the use of biomass as a source of energy [3].

Tobacco plants were widely cultivated in China as an important cigarette material. The tobacco production was 500-550 million tons in China each year. However, tobacco rob (TR) accounted for more than $60 \%$ of the total tobacco plants production which could not be used for cigarette production, and the cost was great to deal with them. Thus, TR was often treated by burning as agricultural wastes. It led to serious environmental problems and enormous waste of resources. So, the reutilization of this waste and the exploitation for potential bioenergy would be indispensable. Thus, this study primarily focused on this feedstock and its experimental results.

Thermogravimetric analysis (TGA) could be a useful tool to study the thermal behaviour of materials. The rate of mass loss as a function of temperature and time was measured and provided a means to estimate the kinetic parameters in the thermal decomposition reaction. The kinetic study of biomass pyrolysis was of relevant importance because it constituted the initial step of the combustion and gasification processes. These data were crucial for efficient modelling, design and operation of pyrolysis process and related thermochemical conversion systems [4]. Many TGA studies had been carried out for pyrolysis of various non-edible biomass sources in the past few decades and established significant information on the pyrolysis behaviour and its kinetics.

\section{Methods}

\subsection{TR Samples}

The tobacco rob (TR) samples used in this study were collected from tobacco waste which was from farm in Enshi City, Hubei Province, China. The samples were dried under the sun for a period of 7 days to reduce the moisture content and then were separated into three different size fractions by sieving, the fractions $0-90 \mu \mathrm{m}$ in size, fractions $90-180 \mu \mathrm{m}$ and fractions 180-380 $\mu \mathrm{m}$. In order to study the kinetics of the process, the particle size has been usually chosen in these ranges by many researchers [5]. Moreover, less than $2 \mathrm{~mm}$ particles size biomass has been used mainly for pyrolysis 
of biomass. The ultimate and proximate analyses and the heating value of the sample were shown in Table. 1

Table 1 Ultimate analysis and proximate analysis of TR

\begin{tabular}{cccc}
\hline \multicolumn{2}{c}{ Ultimate analysis (wt.\%) } & \multicolumn{2}{c}{ Proximate analysis (wt.\%) } \\
\hline C & 43.44 & Moisture content & 10.82 \\
H & 6.596 & Volatile matter & 68.34 \\
O & 36.86 & Fixed carbon & 19.30 \\
N & 0.758 & Ash & 1.54 \\
S & 0.096 & Low heating value (M J/kg) & 20.67 \\
\hline
\end{tabular}

\subsection{Thermogravimetric Analysis}

Thermogravimetric analysis of the TR sample was carried out by TA Instrument system (Diamond TG/DTA, PerkinElmer Instruments). A sample mass of $10 \pm 1.0 \mathrm{mg}$ was used for the thermogravimetric analysis in each experiment. Nitrogen was used as the purge gas for thermal cracking reactions. The flow rate was measured by a volumetric flow meter and was maintained at 40 $\mathrm{ml} / \mathrm{min}$. The heating rate was controlled at a rate $10{ }^{\circ} \mathrm{C} / \mathrm{min}$. The TGA experiments were performed in non-isothermal condition from room temperature to $900{ }^{\circ} \mathrm{C}$ by placing the TR sample in the TGA pan varying the particle size of the sample. Three particle diameter ranges were used in this study, the fractions smaller than $90 \mu \mathrm{m}$, between 90 and $180 \mu \mathrm{m}$ and between 180 and $380 \mu \mathrm{m}$. All experiments were repeated two to three times and reproducible results were successfully achieved.

\section{Results and Discussion}

\subsection{Pyrolysis at Different Particle Sizes}

Thermal decomposition behaviours of TR pyrolysis at three different particle sizes under flowing nitrogen were obtained from Fig. 2. At the temperature lower than $200{ }^{\circ} \mathrm{C}$, the small change of conversion in the samples was attributed to vaporisation of moisture that was cohered on the surface of the samples [6]. The TR samples started to decompose and release volatile matter around $250{ }^{\circ} \mathrm{C}$. The TG curves of the TG showed only two major weight loss stages between 250 and $350{ }^{\circ} \mathrm{C}$, and 350 and $800{ }^{\circ} \mathrm{C}$. It was clear that the slope of the curve changed between the two temperature intervals. Slope between 250 and $350{ }^{\circ} \mathrm{C}$ was higher than that 350 and $800{ }^{\circ} \mathrm{C}$. The conversions at different particle sizes exhibited similar patterns. Since the samples contained mainly cellulose, hemicellulose and lignin, it was known that the hemicellulose started to decompose at around $225-325{ }^{\circ} \mathrm{C}$ and the cellulose was found to decompose between 325 and $375{ }^{\circ} \mathrm{C}$. Lignin had a broad decomposition temperature range at temperatures higher than $250-500{ }^{\circ} \mathrm{C}$. Decomposition at $500{ }^{\circ} \mathrm{C}$ or higher progressed slowly due to the remaining lignin or char, similar to that reported by Fisher [7].

As can be seen in Fig. 2, it was observed at temperatures below $400{ }^{\circ} \mathrm{C}$ that the TG curve shifted slightly to the right with increasing particle size and the DTG curve presented that smaller particle size tended to slightly promote thermal degradation processes towards lower temperature. With increasing particle size, the maximum rate of mass loss increased from $7.83 \% / \mathrm{min}$ to $8.06 \% / \mathrm{min}$. These results could be attributed to two reasons. One is the influence of particle size on the heat transfer since the pyrolysis process mainly occurs in the surface of TR. Larger particles contain greater heat transfer resistance, and hence the actual temperature inside the particle is lower, which leads to the occurrence of a devolatilization process. Subsequently, incomplete pyrolysis results in a large amount of residual char. The other possible reason could be that the pyrolysis process of smaller particle was mainly controlled by reaction kinetics; as the particle size increased, the process was mainly controlled by gas diffusion, since the resultant product gas inside the particle had more difficulty to diffusing out. 


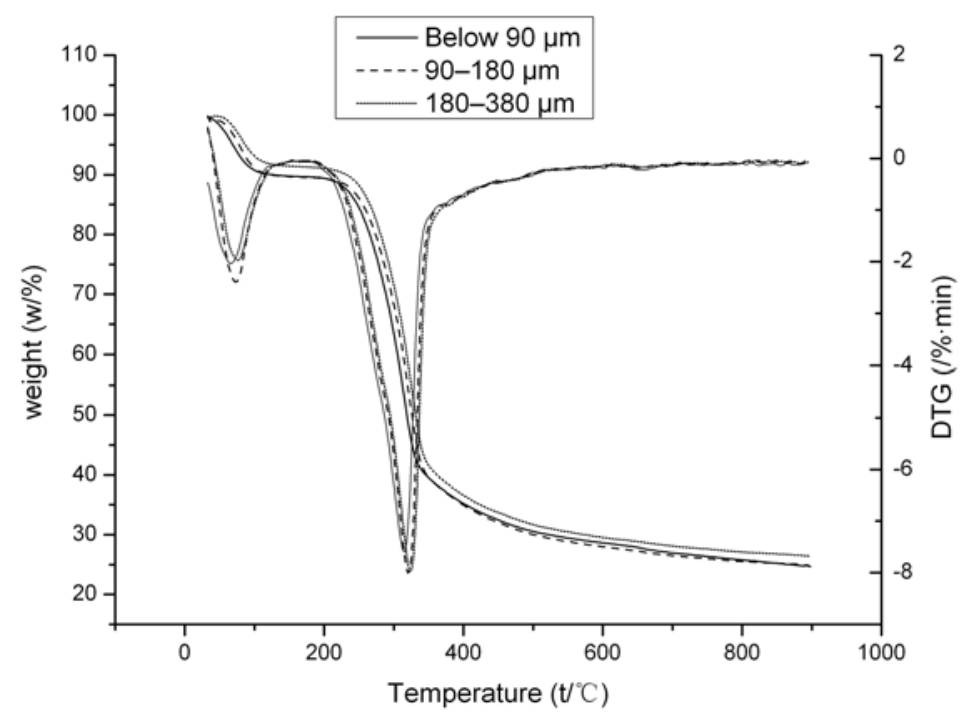

Figure 1. Thermogravimetric behavior of TR at different particle sizes

\subsection{Kinetics Parameters}

Kinetic model was studied for TR pyrolysis to obtain the kinetic parameters including activation energy and pre-exponential factor. The rate of reaction for the decomposition of a solid depended on the temperature and the amount of substance. Thus rate equation for the kinetics analysis could be expressed as:

$d X / d t=k \cdot f(X)$

where $k$ was rate constant, $f(X)$ represented a hypothetical model of reaction mechanism, and $X$ was conversion ratio of biomass feedstock:

$\mathrm{X}=(\mathrm{W} 0-\mathrm{Wt}) /(\mathrm{W} 0-\mathrm{Wf})$

where $W_{0}, W t$ and $W_{f}$ were the initial mass of the sample, the mass of pyrolysis sample, and the final residual mass, respectively. The reaction rate constant $k$ was expressed by the Arrhenius equation:

$\mathrm{k}=\mathrm{Aexp}(-\mathrm{E} / \mathrm{RT})$

where $\mathrm{A}$ was pre-exponential factor, $\mathrm{E}$ was activation energy, $R$ was the universal gas constant, and $\mathrm{T}$ was temperature. Besides, the reaction model in Eq. (1) could be expressed as:

$f(X)=(1-X)^{n}$

where $\mathrm{n}$ was order of reaction. In many applications, the pyrolysis of biomass was assumed to be a first-order reaction (i.e., $\mathrm{n}=1$ ). Therefore, under a constant heating rate $\beta$ (=dT/dt), Eq. (1) could be rearranged to:

$d X / d T=(A / \beta) \cdot \exp (-E / R T) \cdot(1-X)$

By the Doyle integral method [8], Eq. (5) could be integrated to:

$\operatorname{In}[-\operatorname{In}(1-X)]=\operatorname{In}(A R / \beta E)-5.3308-1.0516 \cdot(E / R T)$

For most values of activation energy and for the temperature range of pyrolysis, the term of $\ln (A R / \beta E)$ could be regarded as a constant. Thus a straight line might be obtained from a plot of $\ln [-\ln (1-X)]$ versus $1 / T$. $T$ was the average value of temperatures at which the thermogravimetric data best fit a straight line done by linear regression. From the linear regression of Eq. (6), the activation energy and the pre-exponential factor could be calculated by the slope and the intercept of the line, respectively.

The variation of activation energy as a function of the particle size, calculated using Eq. (6) was presented in Table. 2. It could be seen that all the regression results had nearly extreme coefficients of determination, $R^{2}$ (from 0.9806 to 0.9953 ). Therefore, the assumption that pyrolysis of biomass underwent a first-order reaction should be proper. From Table 2, it can be seen that TR pyrolysis exhibited typical, multi-step reaction characteristics. In the first-step reaction, the activation energy differed with different particle sizes and temperature ranges, and ranged from 53.29 to $58.25 \mathrm{~kJ} / \mathrm{mol}$. The pre-exponential factors varied in the same manner and ranged from $1.6 \times 10^{10}$ to $5.0 \times 10^{10} 1 / \mathrm{s}$. The activation energy and pre-exponential factor for smaller particle size was lower than that for larger 
particle size. The smaller particle significantly increased the rate of reaction, reducing the temperature required to a given percentage conversion by approximately $5-10{ }^{\circ} \mathrm{C}$. During the second-step reaction, the activation energy and pre-exponential factor ranged from 10.85 to 11.64 $\mathrm{kJ} / \mathrm{mol}$ and $6.5 \times 10^{5}$ to $8.5 \times 10^{5}$, respectively. The variation trend was similar to that of the first-step reaction. For both of these steps, the turning points of conversion for TR pyrolysis was about 78 wt.\%. Main decomposition occurred at the conversion from about $15 \%$ to $80 \%$. When the conversion increased above 80\%, the activation energy and pre-exponential factor declined rapidly, which probably attributed to greater presence of residual char.

Table 2. The kinetic analysis of TR pyrolysis at different particle sizes.

\begin{tabular}{cccccc}
\hline & Temperature $\left({ }^{\circ} \mathrm{C}\right)$ & Conversion $(\%)$ & $\mathrm{E}(\mathrm{kJ} / \mathrm{mol})$ & $\mathrm{A}(1 / \mathrm{s})$ & $\mathrm{R} 2$ \\
\hline \multirow{2}{*}{$180-380 \mu \mathrm{m}$} & $248-348$ & $17.57 \sim 79.49$ & 58.25 & $5.0 \times 1010$ & 0.9836 \\
& $348-806$ & $79.49 \sim 99.19$ & 11.64 & $8.5 \times 105$ & 0.9937 \\
\multirow{3}{*}{$90-180 \mu \mathrm{m}$} & $242-345$ & $14.81 \sim 78.16$ & 57.51 & $4.4 \times 1010$ & 0.9856 \\
& $345-785$ & $78.16 \sim 98.89$ & 11.41 & $7.9 \times 105$ & 0.9953 \\
\multirow{3}{*}{ Below $90 \mu \mathrm{m}$} & $238-345$ & $15.99 \sim 77.61$ & 53.29 & $1.6 \times 1010$ & 0.9806 \\
& $345-825$ & $77.61 \sim 98.88$ & 10.85 & $6.5 \times 105$ & 0.9903 \\
\hline
\end{tabular}

\section{Conclusion}

Pyrolytic behaviours of TR at different particle sizes were studied in TGA. Decreasing temperature of the primary decomposition of TR was attributed to a decrease in particle size.The TGA results showed that the conversion rate increased and the activation energy decreased with a decrease in particle size.It was proven that minimizing the size of raw materials was more favorable for gas quality and yield.

\section{References}

[1]. Demirbas MF. Hydrogen from various biomass species via pyrolysis and steam gasification processes. Energy Sources A 2006; 28:245-252.

[2]. Mahinpey N, Murugan P, Mani T, Raina R. Analysis of bio-oil, bio-gas and bio-char from pressurized pyrolysis of wheat straw using a tubular reactor. Energy Fuel 2009; 23:236-242.

[3]. Zaror CA, Hutchings IS, Pyle DL, Stiles HN, Kandiyoti R. Secondary char formation in the catalytic pyrolysis of biomass. Fuel 1985; 64:990-994.

[4]. Sonobe T, Worasuwannarak N. Kinetic analyses of biomass pyrolysis using the distributed activation energy model. Fuel 2008; 87:414-421.

[5]. Li XT, Grace JR, Lim CJ, Watkinson AP, Chen HP, Kim JR. Biomass gasification in a circulating fluidized bed. Biomass Bioenergy 2004; 26:171-193.

[6]. Thangalazhy-Gopakumar S, Adhikari S, Gupta RB, Tu MB, Taylor S. Production of hydrocarbon fuels from biomass using catalytic pyrolysis under helium and hydrogen environments. Bioresour Technol 2011; 102:6742-6749.

[7]. Fisher T, Hajaligol M, Waymack B, Kellogg D. Pyrolysis behavior and kinetics of biomass derived materials. J Anal Appl Pyrol 2003; 62:331-349.

[8]. Starink MJ. The determination of activation energy from linear heating rate experiments: a comparison of the accuracy of isoconversion methods. Thermochimica Acta 2003; 404:63-76. 